\title{
Marked disparity in the epidemiology of tuberculosis among Aboriginal peoples on the Canadian prairies: The challenges and opportunities
}

\author{
Richard Long MD¹, Vernon Hoeppner MD², Pamela Orr MD MSc${ }^{3}$, Martha Ainslie MD³, Malcolm King PhD, \\ Sylvia Abonyi $\mathrm{PhD}^{4}$, Maria Mayan $\mathrm{PhD}^{5}$, Dennis Kunimoto MD¹, Deanne Langlois-Klassen $\mathrm{PhD}^{1}$, \\ Courtney Heffernan MA ${ }^{1}$, Angela Lau BSc ${ }^{1}$, Dick Menzies MD MSc ${ }^{6}$
}

R Long, V Hoeppner, P Orr, et al. Marked disparity in the epidemiology of tuberculosis among Aboriginal peoples on the Canadian prairies: The challenges and opportunities. Can Respir J 2013;20(4):223-230.

BACKGROUND: While it is established that Aboriginal peoples in the prairie provinces of Canada are disproportionately affected by tuberculosis (TB), little is known about the epidemiology of TB either within or across provincial borders.

METHODS: Provincial reporting systems for TB, Statistics Canada censuses and population estimates of Registered Indians provided by Aboriginal Affairs and Northern Development Canada were used to estimate the overall (2004 to 2008) and pulmonary (2007 to 2008) TB rates in the prairie provinces. The place of residence at diagnosis of pulmonary TB cases in 2007 to 2008 was also documented.

RESULTS: The age- and sex-adjusted incidence of TB in Registered Indians was 52.6 per 100,000 person-years, 38 times higher than in Canadian-born 'others'. Incidence rates in Registered Indians were highest in Manitoba and lowest in Alberta. In Alberta and Saskatchewan, onreserve rates were more than twice that of off-reserve rates. Rates in the Métis and Registered Indians were similar in Saskatchewan (50.0 and 52.2 per 100,000 person-years, respectively). In 2007 to 2008, approximately $90 \%$ of Canadian-born pulmonary TB cases in the prairie provinces were Aboriginal. Outside of one metropolitan area (Winnipeg, Manitoba), most Registered Indian and Métis pulmonary TB cases were concentrated in a relatively small number of communities north of the 53rd parallel. Rates of pulmonary TB in 11 of these communities were $>300$ per 100,000 person-years. In Manitoba, 49\% of off-reserve Registered Indian pulmonary cases were linked to high-incidence reserve communities.

INTERPRETATION: The epidemiology of TB among Aboriginal peoples on the Canadian prairies is markedly disparate. Pulmonary TB is highly focal, which is both a concern and an opportunity.

Key Words: Tuberculosis epidemiology; Tuberculosis in Aboriginal peoples
La disparité marquée de l'épidémiologie de la tuberculose au sein des peuples autochtones des Prairies canadiennes : les défis et les occasions
HISTORIQUE : Il est établi qu'un nombre disproportionné de membres des peuples autochtones des Prairies canadiennes est atteint de tuberculose (TB), mais on ne sait pas grand-chose de l'épidémiologie de la TB à l'intérieur des frontières provinciales ou entre ces frontières.

MÉTHODOLOGIE : Les chercheurs ont utilisé les systèmes provinciaux de déclaration de la TB, les recensements de Statistique Canada et les évaluations des populations d'Indiens inscrits fournies par le ministère des Affaires autochtones et du Développement du Nord du Canada pour évaluer le taux de TB global (2004 à 2008) et pulmonaire (2007 et 2008) dans les provinces des Prairies. Ils ont également consigné le lieu de résidence au diagnostic de TB pulmonaire en 2007 et 2008.

RÉSULTATS : L'incidence de TB rajustée selon l'âge et selon le sexe chez les Indiens inscrits était de 52,6 cas sur 100000 personnes-années, un taux 38 fois plus élevé que chez les « autres » d'origine canadienne. Le nombre d'Indiens inscrits atteints de TB était plus élevé au Manitoba et moins élevé en Alberta. En Alberta et en Saskatchewan, les taux sur les réserves étaient presque deux fois plus élevés que ceux hors réserve. Le taux observé chez les Métis et les Indiens inscrits était similaire en Saskatchewan (50,0 et 52,2 cas sur 100000 personnesannées, respectivement). En 2007 et 2008, environ 90 \% des cas de TB pulmonaire chez des habitants d'origine canadienne vivant dans les Prairies s'observaient chez des Autochtones. À l'extérieur d'une région métropolitaine (Winnipeg, au Manitoba), la plupart des cas de TB pulmonaire chez les Indiens inscrits et les Métis se concentraient dans un nombre relativement peu élevé de communautés au nord du $53^{\mathrm{e}}$ parallèle. Le taux de TB pulmonaire dans 11 de ces communautés était de plus de 300 cas sur 100000 personnes-années. Au Manitoba, $49 \%$ des cas de TB pulmonaire chez les Indiens inscrits hors réserve étaient liés à une forte incidence dans les communautés sur les réserves.

INTERPRÉTATION : L'épidémiologie de la TB au sein des peuples autochtones des Prairies canadienne est très disparate. La TB pulmonaire est fortement localisée, ce qui constitue à la fois une inquiétude et une occasion à saisir.

in Canada: First Nations (Registered and non-Registered Indians), Métis and Inuit (7). Of these groups, the Registered Indian and Métis peoples in the provinces of Alberta, Saskatchewan and Manitoba (ie, the 'prairies') contribute more than one-half of the total Aboriginal TB cases in Canada. (3)

The generalization of epidemiological findings in broad population groups, such as Aboriginal and non-Aboriginal, masks the heterogeneity of disease rates (and its associated factors) that exist in Aboriginal communities and that are well known among those who conduct public health fieldwork. An investigation of the epidemiology of TB on the prairies that recognizes the heterogeneity among communities and peoples is a necessary first step in improving our understanding of why TB control is successful in some Aboriginal communities but not in $\mathrm{TB}$ in Aboriginal peoples and colonization $(5,6)$. In 1982, the Constitution Act recognized three major groups of Aboriginal peoples

${ }^{1}$ Department of Medicine, University of Alberta, Edmonton, Alberta; ${ }^{2}$ Department of Medicine, University of Saskatchewan, Saskatoon,

Saskatchewan; ${ }^{3}$ Department of Medicine, University of Manitoba, Winnipeg, Manitoba; ${ }^{4}$ Department of Community Health and Epidemiology,

University of Saskatchewan, Saskatoon, Saskatchewan; ${ }^{5}$ Faculty of Extension, University of Alberta, Edmonton, Alberta; ${ }^{6}$ Department of

Medicine, McGill University, Montreal, Quebec

Correspondence: Dr Richard Long, Room 8325, Aberhart Centre, University of Alberta, 11402 University Avenue, Edmonton, Alberta T6G 2J3.

Telephone 780-407-1427, fax 780-407-1429, e-mail richard.long@ualberta.ca 
others. In turn, strategic planning for TB elimination can be advanced and TB programs better positioned to engage Aboriginal peoples.

The present study aimed to bridge the aforementioned knowledge gap by describing the overall occurrence of TB (2004 to 2008) as well as the incidence of pulmonary TB (2007 to 2008) in different groups of Aboriginal and non-Aboriginal peoples on the prairies and in relation to place of residence. It was hypothesized that the highest rates of culture-confirmed pulmonary TB on the prairies would be associated with Registered Indians living in northern communities as well as with off-reserve members of those communities.

\section{METHODS}

Population

Annual population estimates for Registered Indians living on- and offreserve were acquired directly from Aboriginal Affairs and Northern Development Canada (AANDC). Population estimates for Canadianborn 'others' (comprised of non-Registered Indians, Métis, Inuit and Canadian-born non-Aboriginal people) and foreign-born persons were based on Canadian censuses conducted in 2001 and 2006. Specifically, estimates for Canadian-born 'others' in each census year were calculated by subtracting the Registered Indian population as per AANDC from the census-derived Canadian-born population estimate. For noncensus years, annual population estimates for Canadian-born 'others' and foreign-born persons were derived using linear interpolations (for estimates between the censuses) and linear extrapolations (for estimates in 2007 and 2008).

Disaggregate information for self-identified Métis peoples were also available in each census and calculated for noncensus years using linear interpolation or linear extrapolation. When TB rates for the Métis were estimated, population estimates for non-Métis Canadianborn 'others' (ie, non-Registered Indians, Inuit and Canadian-born non-Aboriginals) were calculated by subtracting the census-derived Métis population estimates and AANDC-provided Registered Indian population estimates from the census-derived Canadian-born population.

Finally, community-level population estimates for communities with two or more pulmonary TB cases reported in 2007 and 2008 were derived through 2001 and 2006 census data using linear extrapolation.

\section{TB cases}

Individuals with active TB are reported to provincial public health authorities in each of the prairie provinces. For the present study, case data were extracted from these electronic provincial TB registries. All notified cases included information regarding patients' country of birth, with anyone born in Canada or in a foreign country to Canadian parents being considered Canadian-born. The Canadian-born population was divided into two primary groups - Registered Indians and Canadian-born 'others' - because of known differences in TB case rates. Where indicated, these primary groups were further differentiated such that cases among Registered Indian peoples were divided into those living on-reserve versus those living off-reserve at the time of diagnosis, and Canadian-born 'others' was further stratified into Métis peoples and non-Métis Canadian-born 'others'.

Two nonexclusive study periods were used in the analysis. The first, spanning 2004 to 2008, was used to describe the overall epidemiology of active $\mathrm{TB}$ cases in the prairie provinces and places into a broader context the observations in the second period. The second period, spanning 2007 to 2008, provided prospective data about Canadianborn adult ( $\geq 15$ years of age) culture-positive pulmonary TB cases ('potential TB transmitters') on the prairies. The prospective study was a component of the Determinants of TB Transmission in the Canadian-born Population of the Prairies project (8).

For each study period, case data included age, sex, population group, province of origin and date of diagnosis (defined as the start date of treatment or the date of death in those who died before treatment could begin). In accordance with Canadian TB Standards (4), pediatric TB cases were defined in the prairie provinces as TB in persons $<15$ years of age as diagnosed through the recovery of Mycobacterium tuberculosis in culture or, more frequently, by a clinical case definition. Most commonly, clinical cases were diagnosed based on the triad of a positive tuberculin skin test (TST); an abnormal chest radiograph and/or physical examination; and an identified link to a known or suspected case of infectious TB. For Registered Indians, case data also included information regarding primary place of residence on the date of diagnosis (defined as the 'usual' place of residence or 'where you lived most of the time') as on-reserve or off-reserve.

For potential TB transmitters in 2007 to 2008, additional data included bacillary status and community of residence at the time of diagnosis. The place of residence of pulmonary TB cases and, especially, those with the greatest potential for transmission (ie, smearpositive cases), was of particular epidemiological interest in the present study as a means of identifying and comparing communities with a high burden of potential transmitters. Each community of residence was classified as a major metropolitan area (Winnipeg [Manitoba], Saskatoon, Regina [Saskatchewan], Edmonton or Calgary [Alberta]), nonmajor metropolitan area (communities $\geq 500$ persons that were not major metropolitan areas), Métis settlement/community or reserve community. Reserve communities in each province consisted of those defined by the First Nations and Inuit Health office in that province. Métis settlements in Alberta were defined in accordance with the Métis Settlements General Council (www.msgc.ca) on account of Alberta being the only province to have land-based Métis settlements. For Saskatchewan and Manitoba, Métis settlements/ communities were identified through the Aboriginal Canada Portal and consist of communities containing $\geq 25 \%$ Métis residents based on Statistics Canada census data. Reserve communities and Métis settlements/communities were further dichotomized according to latitude into northern or southern communities because isolated and more northern communities have been associated with higher TB rates $(9-11)$. For the present study, communities north of the 53rd parallel (the approximate midline of each province) were designated as northern communities and all others as southern communities.

Data for off-reserve Registered Indians diagnosed with pulmonary $\mathrm{TB}$ in each province also included the first three digits of the individual's AANDC number. These data linked these individuals with their reserve community of origin, thereby enabling a preliminary assessment of the reciprocal movement of Registered Indians as a potential pathway for $\mathrm{M}$ tuberculosis transmission.

\section{Statistical analyses}

Associations between the province of diagnosis and the sex, age at diagnosis and population group (Registered Indians, Métis, Canadianborn 'others' and foreign-born) of individuals diagnosed with TB in 2004 to 2008 were assessed using Pearson's $\chi^{2}$ tests or Fisher's exact tests at a $5 \%$ level of significance; two-sided $\mathrm{P}$ values were provided. Similar analyses were completed among individuals diagnosed with pulmonary $\mathrm{TB}$, and particularly smear-positive pulmonary $\mathrm{TB}$, in the second period (2007 to 2008). In each period, incidence rate estimates for the Canadian-born population were reported for on- and offreserve Registered Indians as well as for all other Canadian-born persons (consisting of non-Registered Indians, Métis, Inuit and Canadian-born non-Aboriginal peoples). Rates were adjusted for sex and age at diagnosis using the direct method with the total population of the prairie provinces as the reference population. Incidence rate ratios and $95 \%$ CIs were used to compare rates.

A sensitivity analysis was completed to determine the potential influence of including TB cases among non-Registered Indians with those of Métis cases in Saskatchewan but not in Alberta or Manitoba. To do so, the proportion of all non-Registered Indian and Métis TB cases that were non-Registered Indians was first determined in Alberta and Manitoba. The number of 'Métis' cases in Saskatchewan was then reduced based on the assumption that this proportion was similar in Saskatchewan and the analysis repeated. 
TABLE 1

Population structure in the prairie provinces at mid-study period (2006)

\begin{tabular}{|c|c|c|c|c|}
\hline \multirow[b]{2}{*}{ Population group } & \multicolumn{4}{|c|}{ Population* per $100,000(\%)$} \\
\hline & Alberta & Saskatchewan & Manitoba & Prairie-wide \\
\hline Canadian-born Aboriginal & $1.88(5.8)$ & $1.42(14.9)$ & $1.75(15.5)$ & $5.06(9.5)$ \\
\hline Registered Indian & $0.91(2.8)$ & $0.91(9.5)$ & $1.02(9.0)$ & $2.84(5.3)$ \\
\hline Métis & $0.85(2.6)$ & $0.48(5.0)$ & $0.72(6.3)$ & $2.05(3.8)$ \\
\hline Inuit & $0.02(0.05)$ & $0.002(0.02)$ & $0.01(0.05)$ & $0.02(0.04)$ \\
\hline Canadian-born non-Aboriginal & $25.04(76.9)$ & $7.58(79.5)$ & $7.97(70.3)$ & $40.58(75.9)$ \\
\hline Total & 32.56 & 9.54 & 11.34 & 53.44 \\
\hline
\end{tabular}

*As per the 2006 Statistics Canada census

TABLE 2

Aboriginal communities on the prairies

\begin{tabular}{lrcrrc}
\hline & \multicolumn{2}{c}{ Reserve communities* $^{*}$} & & \multicolumn{2}{c}{ Métis communities $^{\dagger}$} \\
\cline { 2 - 3 } \cline { 6 - 7 } Province & $\mathbf{n}$ & Northern $^{\ddagger} \mathbf{n}(\%)$ & & $\mathbf{n}$ & Northern $^{\ddagger}, \mathbf{n}(\%)$ \\
\hline Alberta & 44 & $34(77.3)$ & & 8 & $8(100.0)$ \\
Saskatchewan & 92 & $52(56.5)$ & & 29 & $23(79.3)$ \\
Manitoba & 63 & $26(41.3)$ & & 13 & $3(23.1)$ \\
Total & 199 & $112(56.3)$ & & 50 & $34(68.0)$ \\
\hline
\end{tabular}

${ }^{*}$ As identified by First Nations Inuit Health, Health Canada; ${ }^{\dagger}$ The number of Métis settlement communities in Alberta was based on information from the Métis Settlements General Council. For Saskatchewan and Manitoba, Métis communities were identified with the Aboriginal Canada portal (www.aboriginalcanada.gc.ca); ${ }^{\ddagger}$ Defined as communities with latitudes north of the 53rd parallel

An a posteriori decision was made to conduct a sensitivity analysis on pediatric TB case rates. To do so, pediatric TB case counts in Saskatchewan were decreased by $4.2 \%$ because a post hoc pediatric TB case review in Saskatchewan indicated that $84 \%$ of pediatric TB cases were culture negative and $5 \%$ of these cases did not meet the typical clinical case definition ( $3 \%$ of cases were TST positive and symptomatic with normal chest radiographs and no known contact with an infectious TB case, while an additional $2 \%$ of cases presented with abnormal chest radiographs and negative TSTs, and were not a contact).

Finally, in relation to the calculation of pulmonary $\mathrm{TB}$ rates in communities with two or more potential transmitters, sensitivity analyses were completed using community-reported population estimates obtained from the Aboriginal Canada portal (www.aboriginalcanada.gc.ca) in place of census-based estimates.

Statistical analyses were conducted using Stata/IC release 11 (StataCorp LP, USA).

Study approval was obtained from the Research Ethics Boards of the Universities of Alberta, Calgary, Saskatchewan and Manitoba, the Regina-Qu'Appelle Health Region and Health Canada.

\section{RESULTS}

The population structure of the prairie provinces at mid-study period (ie, 2006) and the distribution of Registered Indian reserve communities and Métis settlements/communities on the prairies are outlined in Table 1 and Table 2, respectively.

A total of 1792 persons were diagnosed with $\mathrm{TB}$ on the prairies in 2004 through 2008 and notified to provincial public health authorities. Overall, 786 (43.9\%) of these cases were in Registered Indians, 135 (7.5\%) in Métis, 169 (9.4\%) in non-Métis Canadian-born 'others' and $702(39.2 \%)$ in foreign-born individuals (Table 3 ). There were several notable differences in the distribution of $\mathrm{TB}$ cases across the prairies in terms of sex $(\mathrm{P}=0.027)$, age $(\mathrm{P}<0.0001)$ and population group $(\mathrm{P}<0.0001)$ (Table 3). In particular, Registered Indians accounted for a distinctly lower proportion of cases in Alberta than Saskatchewan $(\mathrm{P}<0.0001)$ or Manitoba $(\mathrm{P}<0.0001)$, whereas the proportion of Métis
TABLE 3

Demographic characterisitics of tuberculosis cases in the prairie provinces of Canada, 2004 to 2008

\begin{tabular}{|c|c|c|c|c|}
\hline \multirow{2}{*}{$\begin{array}{l}\text { Demographic } \\
\text { group }\end{array}$} & \multicolumn{3}{|c|}{ Province* $^{*}$} & \multirow{2}{*}{$\begin{array}{l}\text { Prairie } \\
\text { wide }\end{array}$} \\
\hline & $A B$ & SK & MB & \\
\hline Assessed & $663(37.0)$ & $492(27.5)$ & 637 (35.5) & $1792(100.0)$ \\
\hline \multicolumn{5}{|l|}{ Age, years } \\
\hline$<15$ & $35(5.3)$ & $149(30.3)$ & $65(10.2)$ & $249(13.9)$ \\
\hline $15-34$ & 201 (30.3) & $177(36.0)$ & $236(37.0)$ & $614(34.3)$ \\
\hline $35-64$ & 259 (39.1) & $139(28.3)$ & $273(42.9)$ & 671 (37.4) \\
\hline$>64$ & 168 (25.3) & $27(5.5)$ & $63(9.9)$ & $258(14.4)$ \\
\hline \multicolumn{5}{|l|}{ Sex } \\
\hline Male & 331 (49.9) & $268(54.5)$ & 365 (57.3) & $964(53.8)$ \\
\hline Female & 332 (50.1) & $224(45.5)$ & $272(42.7)$ & $828(46.2)$ \\
\hline \multicolumn{5}{|l|}{ Population group ${ }^{\dagger}$} \\
\hline Registered Indians & $60(9.0)$ & $321(65.2)$ & $406(63.7)$ & 787 (43.9) \\
\hline Métis & $15(2.3)$ & $115(23.4)$ & $5(0.8)$ & $135(7.5)$ \\
\hline Non-Métis CBO & 77 (11.6) & $22(4.5)$ & $69(10.8)$ & $168(9.4)$ \\
\hline Foreign born & 511 (77.1) & $34(6.9)$ & $157(24.6)$ & 702 (39.2) \\
\hline
\end{tabular}

Data presented as $n$ (\%). *Three patients were not included in the analysis on account of missing data; 'Non-Métis Canadian-born 'others' (CBO) included eight non-Registered Indians and three Inuit. In Saskatchewan, non-Registered Indians were included with Métis within the provincial TB registry. AB Alberta; MB Manitoba; SK Saskatchewan

cases was notably higher in Saskatchewan compared with the other two prairie provinces $(\mathrm{P}<0.0001$ for each). In the present study, eight (28.57\%) of the 28 TB cases among non-Registered Indian and Métis peoples in Alberta and Manitoba were non-Registered Indians. Based on the assumption that this proportion was similar in Saskatchewan, a sensitivity analysis was performed whereby the total number of Métis cases (which included non-Registered Indians due to the coding within the TB Registry) in Saskatchewan in 2004 to 2008 was reduced by the anticipated number of TB cases among non-Registered Indians $(115$ cases $-[115 \times 0.2857]=82)$. Using this adjusted case count for 'Métis only' cases, the proportion of TB cases in Saskatchewan that were Métis continued to be significantly higher than either Alberta $(\mathrm{P}<0.0001)$ or Manitoba $(\mathrm{P}<0.0001)$. Unlike Saskatchewan and Manitoba, nearly three-quarters of cases in Alberta were among foreignborn persons ( $\mathrm{P}<0.0001$ for each).

In relation to sex, a higher proportion of cases were male in Manitoba compared with Alberta $(\mathrm{P}=0.008)$; the proportion of male cases in Saskatchewan was similar to that of Alberta $(\mathrm{P}=0.126)$ and Manitoba $(\mathrm{P}=0.342)$. In terms of age at diagnosis, the proportion of cases that were pediatric $(<15$ years of age $)$ was higher in Saskatchewan than in Manitoba $(\mathrm{P}<0.0001)$ or Alberta $(\mathrm{P}<0.0001)$, whereas Alberta had a higher proportion of elderly $(>64$ years of age) cases $(\mathrm{P}<0.0001$ for each). The proportion of pediatric cases in Saskatchewan continued to be significantly higher than the other two provinces in the 
TABLE 4

Tuberculosis case rates in the Canadian-born popuation of the prairie provinces according to province, population group and place of residence at diagnosis, 2004 to 2008

\begin{tabular}{|c|c|c|c|c|c|c|}
\hline \multirow[b]{2}{*}{ Province } & \multirow[b]{2}{*}{ Population group* } & \multirow{2}{*}{$\begin{array}{c}\text { Place of } \\
\text { residence }^{\dagger}\end{array}$} & \multirow[b]{2}{*}{ Cases, $\mathrm{n}$} & \multirow[b]{2}{*}{ PYs $(100,000 \mathrm{~s})$} & \multicolumn{2}{|c|}{ Incidence rate $(95 \% \mathrm{Cl})$} \\
\hline & & & & & Unadjusted $^{\ddagger}$ & Adjusted $^{\ddagger}$ \\
\hline \multirow[t]{4}{*}{ Alberta } & Registered Indians & On & 43 & 3.2 & $13.6(9.5-17.7)$ & $27.0(21.3-32.8)$ \\
\hline & & Off & 17 & 1.8 & $9.7(5.1-14.3)$ & $11.6(6.5-16.6)$ \\
\hline & Canadian-born 'others' & - & 92 & 131.4 & $0.7(0.6-0.8)$ & $0.8(0.6-0.9)$ \\
\hline & All Canadian born & - & 152 & 136.3 & $1.11(0.9-1.3)$ & $1.2(1.0-1.4)$ \\
\hline \multirow[t]{4}{*}{ Saskatchewan } & Registered Indians & On & 222 & 3.1 & $72.2(62.7-81.7)$ & $72.0(62.5-81.4)$ \\
\hline & & On and off & 321 & 6.1 & $52.2(46.5-58.0)$ & $52.9(47.2-58.7)$ \\
\hline & Canadian-born 'others' & - & 137 & 39.6 & $3.5(2.9-4.0)$ & $3.6(3.0-4.2)$ \\
\hline & All Canadian born & - & 458 & 45.7 & $10.0(9.1-10.9)$ & $10.2(9.3-11.1)$ \\
\hline \multirow[t]{3}{*}{ Manitoba } & Registered Indians & On & 269 & 3.9 & $68.8(60.6-77.0)$ & $83.3(74.2-92.3)$ \\
\hline & & Off & 137 & 2.3 & $59.6(49.4-69.2)$ & $68.1(57.5-78.8)$ \\
\hline & & On and off & 406 & 6.2 & $65.3(58.9-71.6)$ & $77.0(70.1-83.9)$ \\
\hline \multirow{4}{*}{ Prairie-wide } & & Off & 253 & 7.1 & $35.4(31.1-39.8)$ & $40.0(35.4-44.6)$ \\
\hline & & On and off & 787 & 17.3 & $45.5(42.4-48.7)$ & $52.6(49.2-56.0)$ \\
\hline & Canadian-born 'others' & - & 303 & 214.1 & $1.4(1.3-1.6)$ & $1.4(1.3-1.6)$ \\
\hline & All Canadian born & - & 1090 & 231.3 & $4.7(4.4-5.0)$ & $4.7(4.4-5.0)$ \\
\hline
\end{tabular}

${ }^{*}$ Canadian-born 'others' includes non-Registered Indians, Métis, Inuit and Canadian-born non-Aboriginals.; ${ }^{\dagger}$ Place of residence refers to on-reserve (On) or offreserve (Off); ${ }^{\ddagger}$ Rate estimates are per 100,000 person-years (PYs) of observation

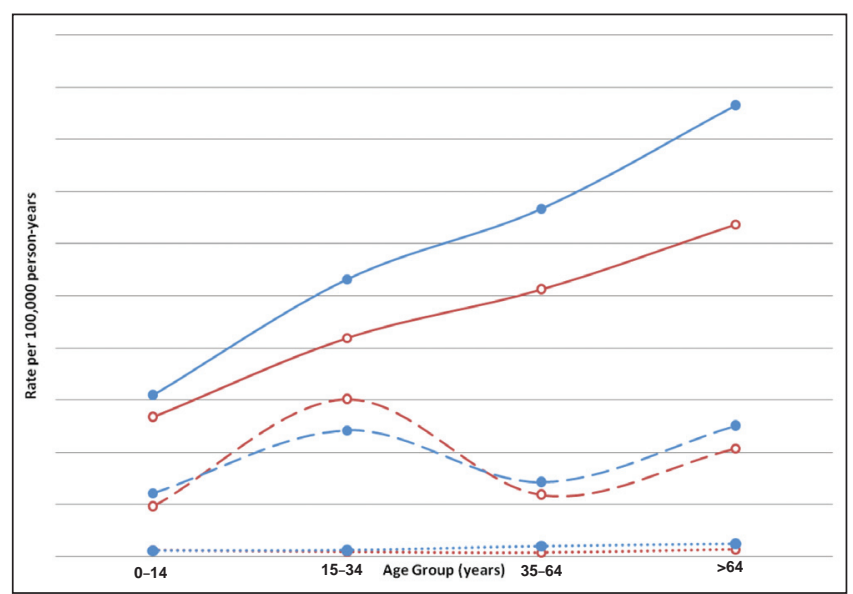

Figure 1) Age-sex specific tuberculosis case rates per 100,000 personyearsin the Prairie Provinces, 2004 to 2008. Rates for male cases are indicated closed (solid) circles and rates for females by open circles. Lines represent different population groups: solid lines, cases among Registered Indians; dashed lines, foreign-born cases; dotted lines, Canadian-born 'others' cases

sensitivity analysis, which adjusted for the potential use of a more inclusive clinical case definition in Saskatchewan $(\mathrm{P}<0.0001)$.

Of the pediatric TB cases, a similar proportion were male and $<5$ years of age in each province $(\mathrm{P}=0.538$ and $\mathrm{P}=0.267$, respectively). Specifically, two (50.0\%) cases in Alberta, 59 (56.2\%) in Saskatchewan and $23(42.6 \%)$ in Manitoba were $<5$ years of age at diagnosis. There was, however, significant variation in the population groups of pediatric cases among the prairie provinces $(\mathrm{P}<0.0001)$. In particular, most pediatric cases in Saskatchewan $(\mathrm{n}=105[70.5 \%])$ and Manitoba ( $n=54$ [83.1\%]) were Registered Indians, whereas Registered Indians contributed the smallest proportion of pediatric cases in Alberta $(n=4$ [11.4\%]). The majority of cases in Alberta occurred among foreignborn children $(n=19$ [54.3\%]), whereas three (2.0\%) and eight $(12.3 \%)$ cases were foreign-born in Saskatchewan and Manitoba, respectively. Despite these differences, a similar proportion of Registered Indian children with TB resided on-reserve in each province with three (75.0\%) on-reserve pediatric cases in Alberta, 81 (77.1\%) cases in Saskatchewan and $41(75.9 \%)$ cases in Manitoba $(\mathrm{P}=0.982)$.

Overall, the age- and sex-adjusted incidence of TB in Registered Indians on the prairies in 2004 to 2008 was 52.6 per 100,000 personyears (Table 4). Moving from east to west, the adjusted rate per 100,000 person-years fell from 77.0 in Manitoba to 52.9 in Saskatchewan $(\mathrm{P}<0.0001)$ and then to 20.4 in Alberta $(\mathrm{P}<0.0001)$ (Table 4). There were marked disparities in the TB rates of Registered Indians in each province, the rates being 45 times, 26 times and 15 times that of Canadian-born 'others' in Manitoba, Alberta and Saskatchewan, respectively $(\mathrm{P}<0.0001$ for each). Rate disparities were also associated with the place of residence of Registered Indians (Table 4). In both Alberta and Saskatchewan, the adjusted on-reserve TB rate was nearly twice that of off-reserve Registered Indians $(\mathrm{P}=0.034$ and $\mathrm{P}=0.0003$, respectively) while it was 1.2 times higher in Manitoba $(\mathrm{P}<0.0001)$. Métis rates were much higher in Saskatchewan than in Alberta or Manitoba $(\mathrm{P}<0.0001$ for each), and similar in Alberta and Manitoba $(\mathrm{P}=0.066)$ (data not shown).

Prairie-wide, the TB rates of females and males increased incrementally with age in Registered Indians and Canadian-born 'others' with the peak rate occurring among those $>64$ years of age at diagnosis (Figure 1). This contrasted with the age-specific rates in the foreignborn, which had a double peak in rates at ages 15 to 34 and $>64$ years. At age $>64$ years, Registered Indian females and males had rates that were 44 times $(\mathrm{P}<0.0001)$ and 33 times $(\mathrm{P}<0.0001)$ that of Canadianborn 'others' females and males, respectively. Among Registered Indians, males had higher rates in each age group, the rate difference increasing with age. Similar rates were observed between males and females among foreign-born and Canadian-born 'others' cases.

In 2007 to 2008, there were 248 adult ( $\geq 15$ years of age) Canadianborn culture-positive pulmonary $\mathrm{TB}$ cases on the prairies. Of these, $145(58.5 \%)$ were sputum smear-positive and, therefore, more infectious (Table 5). Overall, most pulmonary cases were $\leq 64$ years of age (91.9\%), male (59.3\%) and Registered Indian (73.4\%). Smear-positive cases were more common in Métis and non-Métis Canadian-born 'others' than 
TABLE 5

Culture-positive pulmonary tuberculosis in the adult Canadian-born population of the prairie provinces according to age, sex and population group, 2007 to 2008

\begin{tabular}{|c|c|c|c|c|c|c|c|c|}
\hline \multirow{2}{*}{$\begin{array}{l}\text { Demographic } \\
\text { group }\end{array}$} & \multicolumn{2}{|c|}{ Alberta } & \multicolumn{2}{|c|}{ Saskatchewan } & \multicolumn{2}{|c|}{ Manitoba } & \multicolumn{2}{|c|}{ Prairie-wide } \\
\hline & Cases & $\mathrm{S}+$ & Cases & $\mathrm{S}+$ & Cases & $\mathrm{S}+$ & Cases & $\mathrm{S}+$ \\
\hline Assessed, $\mathrm{n}$ & 37 & $26(70.3)^{\star}$ & 86 & $60(69.8)^{\star}$ & 125 & $59(47.2)^{\star}$ & 248 & $145(58.5)^{\star}$ \\
\hline \multicolumn{9}{|l|}{ Age, years } \\
\hline $35-64$ & $22(59.5)$ & $17(65.4)$ & $42(48.8)$ & $31(51.7)$ & $71(56.8)$ & $31(52.5)$ & $135(54.4)$ & $79(54.5)$ \\
\hline$>64$ & $6(16.2)$ & $2(7.7)$ & $5(5.8)$ & $4(6.7)$ & $9(7.2)$ & $5(8.5)$ & $20(8.1)$ & $11(7.6)$ \\
\hline Female & $13(35.1)$ & $10(38.5)$ & $41(47.7)$ & $30(50.0)$ & 47 (37.6) & $29(49.2)$ & $101(40.7)$ & $69(47.6)$ \\
\hline \multicolumn{9}{|l|}{ Population group $^{\dagger}$} \\
\hline Registered Indian & $18(48.6)$ & $11(42.3)$ & $54(62.8)$ & $34(56.7)$ & $110(88.0)$ & $47(79.7)$ & $182(73.4)$ & $92(63.4)$ \\
\hline Métis & $6(16.2)$ & $5(19.2)$ & $26(30.2)$ & $20(33.3)$ & $6(4.8)$ & $5(8.5)$ & 38 (15.3) & $30(20.7)$ \\
\hline Non-Métis CBO & $13(35.1)$ & $10(38.5)$ & $6(7.0)$ & $6(10.0)$ & $9(7.2)$ & $7(11.9)$ & $28(11.3)$ & 23 (15.9) \\
\hline
\end{tabular}

Data presented as $n$ (\%) unless otherwise indicated. ${ }^{*}$ Percentage of cases that were smear positive $(\mathrm{S}+)$; ${ }^{\dagger}$ Canadian-born 'others' (CBO) includes two known nonRegistered Indians and one Inuit. In Saskatchewan, non-Registered Indians are included with Métis within the provincial tuberculosis registry

TABLE 6

Culture-positive pulmonary tuberculosis case rates in the Canadian-born population of the prairie provinces according to province, population group and place of residence, 2007 to 2008 *

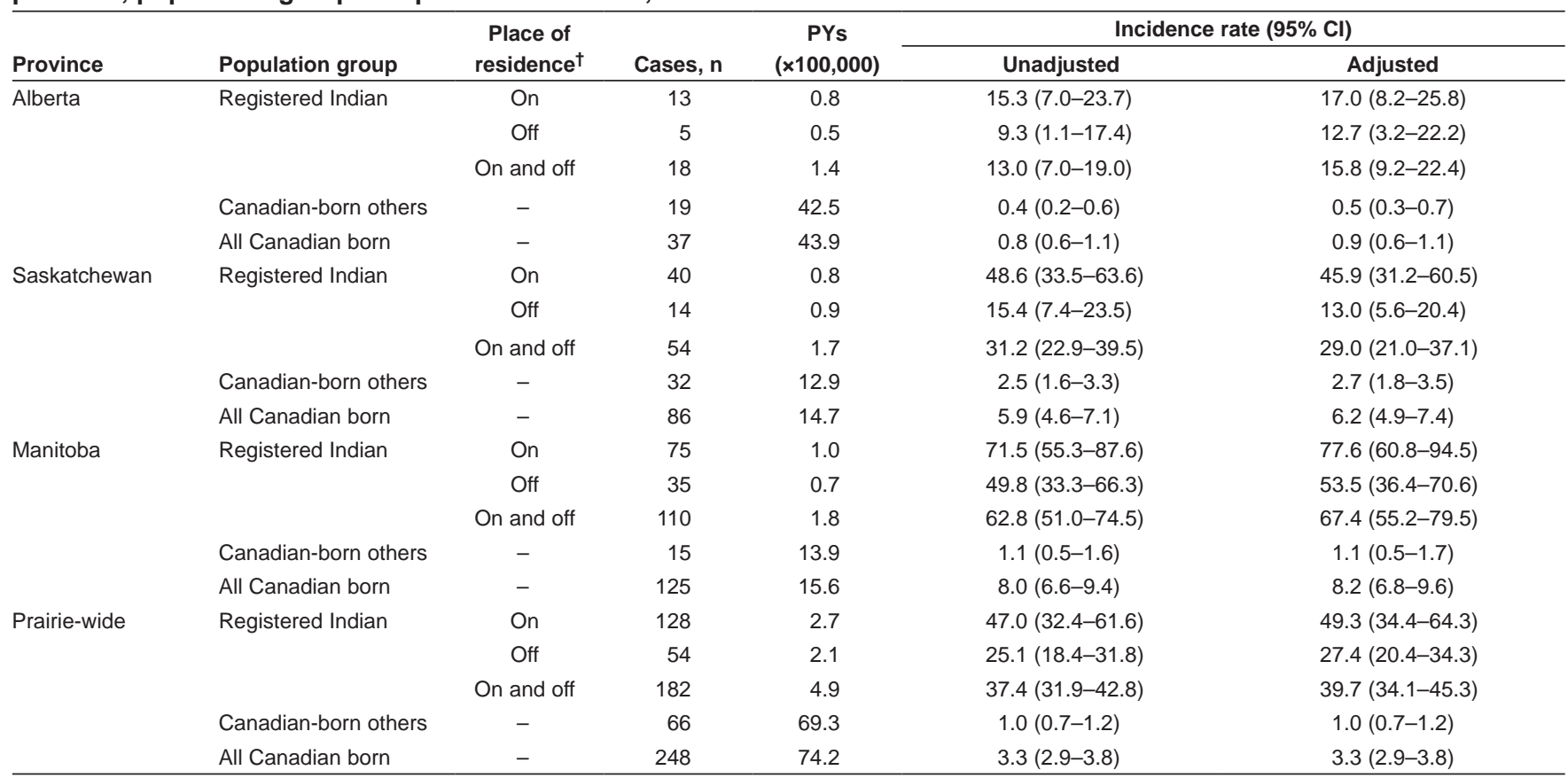

${ }^{*}$ Canadian-born 'others' includes non-Registered Indians, Métis, Inuit and Canadian-born non-Aboriginals; ${ }^{\dagger}$ Place of residence refers to on- or off-reserve; ${ }^{\ddagger}$ Rate estimates are per 100,000 person-years (PYS) of observation

Registered Indian cases $(\mathrm{P}<0.0001)$ (Table 5$)$. Although $85 \%$ of pulmonary TB cases on the prairies occurred in Manitoba and Saskatchewan, the frequency of smear-positive cases was highest in Alberta and Saskatchewan ( $\mathrm{P}=0.001)$ (Table 5).

The age- and sex-adjusted incidence of pulmonary TB in Registered Indians on the prairies was 39.7 per 100,000 person-years in 2007 to 2008 (Table 6). This rate was 40 times higher than that of Canadianborn 'others' $(\mathrm{P}<0.0001)$. The adjusted rate of pulmonary TB in Registered Indians was also higher than that of Canadian-born 'others' in each province (Table 6), the ratio being higher in Manitoba (61 times) than Alberta (32 times) or Saskatchewan (11 times). Furthermore, although the prairie-wide adjusted rates of pulmonary TB was 1.8 times higher in on-reserve than off-reserve Registered Indians (Table 6), the ratio was remarkably higher in Saskatchewan (3.5 times) than Manitoba (1.5 times) or Alberta (1.3 times).
The distribution of pulmonary TB according to community of residence at the time of diagnosis was highly focal: outside of the major metropolitan areas, only 47 (23.6\%) of 199 reserve communities (Figure 2), five (10.0\%) of 50 Métis settlements/communities and $18(2.5 \%)$ of 726 nonmajor metropolitan areas reported a pulmonary TB case. Of the 112 reserve communities that were north of the 53rd parallel and the 87 reserve communities that were south of it, $17(15.2 \%)$ and four (4.6\%) had two or more pulmonary TB cases, respectively. Of the 157 on-reserve Registered Indian and in-settlement/ community Métis pulmonary TB cases, 131 (83.4\%) resided north of the 53rd parallel. Ten reserve communities and one Métis settlement, all north of the $53 \mathrm{rd}$ parallel, had pulmonary TB case rates of $>300$ per 100,000 person-years in 2007 to 2008. The sensitivity analysis, which used census-based population estimates in place of community-reported estimates, found that all but one of these communities continued to 


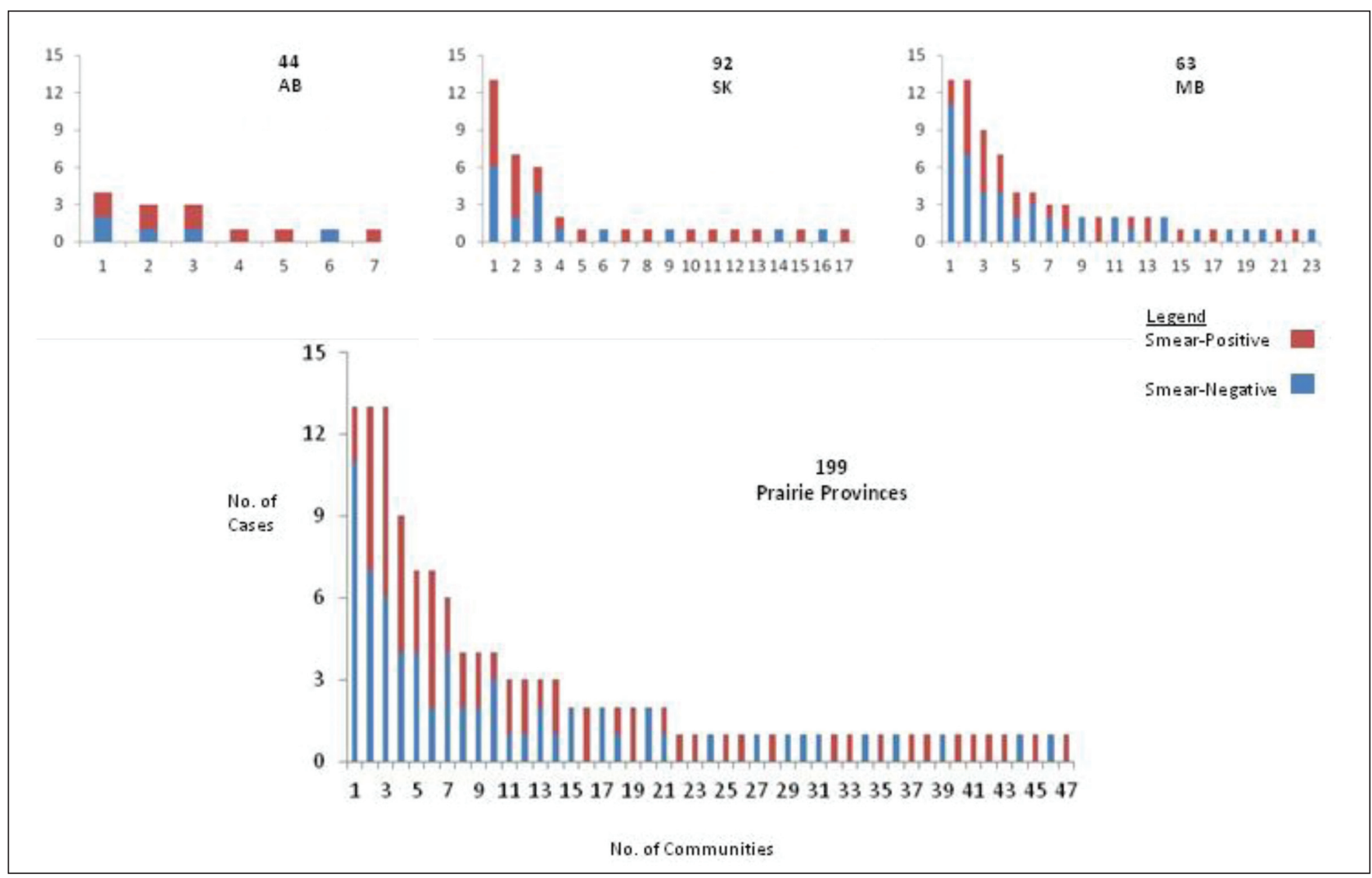

Figure 2) Frequency distribution of Registered Indian pulmonary tuberculosis cases according province, reserve community and sputum smear status in 2007 to 2008. Numbers written over the provincial abbreviations refer to the total number of reserve communities in each jurisdiction. AB Alberta; SK Saskatchewan; MB Manitoba; No Number

TABLE 7

Culture-positive pulmonary tuberculosis in the adult Canadian-born population of the major metropolitan areas on the prairies according to population group and smear status, 2007 to 2008

\begin{tabular}{|c|c|c|c|c|c|c|c|c|}
\hline \multirow[b]{3}{*}{ Major metropolitan area } & \multicolumn{6}{|c|}{ Population group* } & & \\
\hline & \multicolumn{2}{|c|}{ Registered Indian } & \multicolumn{2}{|c|}{ Métis } & \multicolumn{2}{|c|}{ Canadian-born 'other' } & \multicolumn{2}{|c|}{ Total } \\
\hline & Cases & S+ & Cases & $\mathrm{S}+$ & Cases & $\mathrm{S}+$ & Cases & S+ \\
\hline Assessed, $\mathrm{n}$ & 38 & $23(60.5)$ & 9 & 8 (88.9) & 18 & $14(77.8)$ & 65 & $45(69.3)$ \\
\hline Calgary, Alberta & $0(0.0)$ & $0(0.0)$ & $0(0.0)$ & $0(0.0)$ & $3(16.7)$ & $3(100.0)$ & $3(4.6)$ & $3(100.0)$ \\
\hline Edmonton, Alberta & $2(5.3)$ & $1(50.0)$ & $3(33.3)$ & $3(100.0)$ & $5(27.8)$ & $3(60.0)$ & $10(15.4)$ & $7(70.0)$ \\
\hline Saskatoon, Saskatchewan & $5(13.2)$ & $5(100.0)$ & $1(1.1)$ & $1(100.0)$ & $1(5.6)$ & $1(100.0)$ & $7(10.8)$ & $7(100.0)$ \\
\hline Regina, Saskatchewan & $4(10.5)$ & $3(75.0)$ & $1(1.1)$ & $1(100.0)$ & $2(11.1)$ & $2(100.0)$ & $7(10.8)$ & $6(85.8)$ \\
\hline Winnipeg, Manitoba & $27(71.0)$ & $14(51.9)$ & $4(44.4)$ & $3(75.0)$ & $7(38.9)$ & $5(71.5)$ & $38(58.4)$ & $22(57.9)$ \\
\hline
\end{tabular}

Data presented as n (\%) unless otherwise indicated. *Métis includes one known non-Registered Indian, Canadian-born 'others' includes one Inuit. S+ Smear-positive cases

have pulmonary TB rates $>300$ cases per 100,000 person-years. The other community had a pulmonary TB rate of 291 per 100,000 personyears in the sensitivity analysis.

Of the five major metropolitan areas on the prairies, Winnipeg (Manitoba) had more pulmonary TB cases than the other four combined (Table 7). Consequently, the rate of pulmonary TB in the Registered Indians of Winnipeg (157.8 per 100,000 person-years) was two to 158 times that of Regina, Saskatoon, Edmonton or Calgary (rates of 68.3, 73.0, 14.1, and 0 per 100,000 person-years, respectively). Of the five, 14, and 35 off-reserve Registered Indian pulmonary TB cases in Alberta, Saskatchewan and Manitoba, respectively, one (20.0\%), three $(21.4 \%)$ and $17(48.6 \%)$ were linked by AANDC numbers to reserve communities that reported two or more pulmonary TB cases $(\mathrm{P}=0.999)$.

\section{DISCUSSION}

The present study highlights the persistence of markedly disparate TB rates on the Canadian prairies in Aboriginal peoples compared with Canadian-born 'others'. Overall, Registered Indians had an age- and sex-adjusted TB incidence rate that was 38 times that of other Canadian-born individuals (range 15 to 45 times in the individual prairie provinces). Marked disparities in the incidence of TB among Registered Indians were also evident among the three prairie provinces, the TB rates increasing in a west to east direction (the lowest and highest rates being in Alberta and Manitoba, respectively). This result contrasts with the prevailing view that the incidence of TB in Registered Indians in Canada varies inversely with time since first European contact, which occurred in an east to west direction $(3,6,12)$. Saskatchewan was unique in that it was the only province in 
which Métis and Registered Indians had similar TB rates. Pediatric cases, indicative of ongoing transmission, were also most common in Saskatchewan. The place of residence of Registered Indians was another important predictor of $\mathrm{TB}$ rates in two provinces (Alberta and Saskatchewan) given that on-reserve rates were nearly twice that of offreserve rates. That the on- and off-reserve rates in Manitoba were similar is possibly explained by the finding that almost one-half of all off-reserve Registered Indian cases in that Province were linked by AANDC number to reserve communities with two or more pulmonary cases.

Furthermore, with respect to place of residence, we found that the geographical distribution of adult Canadian-born pulmonary TB cases on the prairies (approximately 90\% of whom were Aboriginal) was highly focal. With the exception of the major metropolitan area of Winnipeg, most Registered Indian and Métis pulmonary TB cases were concentrated in a relatively small number of reserve communities and Métis settlements/communities in the northern portion of each province. Several of these northern communities also had pulmonary TB rates comparable with those in developing countries ( $>300$ cases per 100,000 person-years). This epidemiological picture is interpreted within a historical context.

Epidemic TB among First Nations peoples on the prairies arose in the late 1870 s and early 1880 s following a series of cataclysmic ecological, economic and political events. These events included the near extermination of buffalo, loss of ancestral lands through treaties, confinement to reserves and the creation of the residential school system. $(5,13)$ At its peak in 1886 , TB mortality in First Nations was estimated to be 9000 per 100,000 persons; with death rates exceeding birth rates for many years, the spectre of extinction of First Nations peoples was raised (14). Nearly 100 years later (1970 to 1981) and after a combination of natural selection, acquired immunity, sanatorium treatment, bacille-Calmette-Guérin vaccination, chemotherapy, chemoprophylaxis and modest improvements in socioeconomic status $(5,13-16)$, the TB morbidity rate in First Nations on the prairies was 161 per 100,000 persons (TB deaths were fortunately too few to provide a meaningful epidemiological index) (3).The results of the current study highlight that further reductions in the TB morbidity rate of First Nations peoples on the prairies were achieved between 2004 and 2008 (52.6 per 100,000 person-years).

However, for reasons that remain unclear, the present study found that the usual east-west TB incidence gradient has been reversed $(3,6,10)$. Moreover, extraordinarily high rates of pulmonary TB indicate that the disease has become entrenched in selected northern communities and one major metropolitan area. The latter presents both reasons for concern and, more importantly, opportunity for intervention.

Concerns about persistent TB in middle northern communities are not new, with one report from Manitoba dating back to $1925(10,11,17$ 19). Causes for concern include social disruption, a formidable obstacle to TB control in many Aboriginal communities due to its association with colonialism (20-22). Summary statistics, such as the overall provincial TB estimates provided in the present study, while convenient and technically correct, inadvertently obscure the cultural diversity and relative resilience of Aboriginal communities $(23,24)$. That TB primarily affects minority groups and is increasingly focal also raises concerns about funding. Funding concerns for diseases, such as TB and HIV, are further accentuated by the blurring of federal and provincial public health jurisdictional lines through the on-reserve/off-reserve mobility of Aboriginal peoples (25-29). Finally, geography itself challenges equitable administrative and provider responses (30).

In terms of opportunities, the concentration of pulmonary TB in a limited number of communities allows for a 'high burden' as opposed to a 'population'-based approach. This affords the community a greater opportunity to have direct involvement in the selection and implementation of the programs that are to be undertaken (31). Issues related to on-reserve/off-reserve mobility highlight the need for improved stakeholder collaboration. Enhanced collaboration and consultation among provincial and federal TB controllers as well as First
Nations would also be beneficial given that apparent contradictions exist within Treaty areas that cross provincial boundaries - namely, that the same Treaty area might have a different TB epidemiology in each province. Finally, with respect to geographical barriers, it has been demonstrated that different delivery models can enhance TB program performance (32).

The significantly higher prevalence of pediatric TB in Saskatchewan suggests one of three things: that, because most pediatric cases are culture-negative and the diagnosis is dependent on a clinical case definition, a more sensitive pediatric case definition was applied in that province that perhaps reflects interprovincial variation in the radiological identification of pediatric TB cases; there is a higher incidence of pediatric TB in Saskatchewan relative to Alberta and Manitoba; or a combination of the former two.

Among off-reserve Registered Indians, the situation in Winnipeg is clearly exceptional and raises the possibility that mobility between Winnipeg and reserve communities is sustaining disease prevalence (24). However, our data are limited in this regard. Estimation of Métis rates was another limitation because information regarding Métis status is not systematically collected at the time of diagnosis of TB and census-based population estimates are dependent on self-identification as Métis. Another study limitation relates to non-Registered Indians and Métis peoples being coded together in the TB Registry in Saskatchewan. Consequently, the ability to describe the occurrence of TB in Métis peoples was not consistent in each province. Despite this limitation, the reporting of TB data for Métis peoples was considered to be highly valuable due to the paucity of published literature in this subject area. The necessity of including TB cases among non-Registered Indians with those of Métis peoples in Saskatchewan was anticipated to have a minimal influence on the study results because non-Registered Indians only comprised $0.3 \%$ of the total population in Saskatchewan in 2006 ( $0.3 \%$ in Alberta and $0.1 \%$ in Manitoba) and $5.6 \%$ of the subpopulation of Métis and non-Registered Indians (Statistics Canada).The results of the sensitivity analysis also suggested that the inclusion of TB cases among non-Registered Indians with those of Métis peoples did not significantly influence the study results.

The collection, analysis and presentation of the data in the present study, including specific comparisons, followed an inclusory process of consultations and approvals involving governments, universities and Aboriginal communities. (8) Data were openly discussed at provincial and prairie-wide meetings of TB stakeholders and Aboriginal peoples organized in accordance with national guidelines for health research involving Aboriginal peoples $(8,33,34)$. Its interpretation reflects those discussions.

Similar to Canada overall, TB case rates in Aboriginal and nonAboriginal Canadian-born people on the prairies remain markedly disparate. Although there has been some progress when viewed over an extended period of time, progress could be accelerated if the current epidemiology and geographical distribution of cases are taken into account.

ACKNOWLEDGEMENTS: The authors thank the staff and trainees in the Tuberculosis Program Evaluation and Research Unit at the University of Alberta, and staff in the University of Saskatchewan and University of Manitoba for their assistance in preparing the manuscript. The authors acknowledge the assistance of the Governments of Alberta, Saskatchewan and Manitoba, in compiling the data. The results and conclusions reported in this paper are those of the authors and no official endorsement of the respective Governments is intended or should be inferred. As co-investigators on "The Determinants of Tuberculosis Transmission in the Canadian-born Population of the Prairie Provinces" project $\mathrm{RL}, \mathrm{VH}, \mathrm{PO}, \mathrm{MA}, \mathrm{MK}, \mathrm{SA}, \mathrm{MM}, \mathrm{DK}$ and $\mathrm{DM}$ contributed to the design and conduct of the study. RL, DL-K, CH and AL analyzed the data and wrote the manuscript.

FUNDING: Funding for this study was provided by the Canadian Institutes of Health Research and the First Nations and Inuit Health Branch, Health Canada. 


\section{REFERENCES}

1. Brancker A, Enarson DA, Grzybowski S, Hershfield ES, Jeanes CWL. A statistical chronicle of tuberculosis in Canada: Part I.

From the era of sanatorium treatment to the present. Part II. Risk today and control. Statistics Canada, Cat. 82-003. Health Reports 1992;4:103-23;277-92.

2. Tuberculosis in Canada 2009-Pre-release. Public Health Agency of Canada. Minister of Public Works and Government Services Canada, 20109. <www.publichealth.gc.ca/tuberculosis> (Accessed October 26, 2012).

3. Enarson DA, Grzybowski S. Incidence of active tuberculosis in the native population of Canada. CMAJ 1986;134:1149-52.

4. The Canadian Tuberculosis Standards, 6th edn. The Canadian Lung Association and the Public Health Agency of Canada, 2007. <www. publichealth.gc.ca/tuberculosis> (Accessed September 5, 2012).

5. Wherrett GJ. The miracle of the empty beds: A history of tuberculosis in Canada. Toronto: University of Toronto Press; 1977.

6. Hoeppner V, Marciniuk DD. Tuberculosis in Aboriginal Canadians. Can Respir J 2000;7:141-6.

7. Canadian Charter of Rights and Freedoms. Constitution Act, 1982(1). <www.solon.org/Constitutions/Canada/English/ca_1982. html> (Accessed September 5, 2012).

8. Boffa J, King M, McMullin K, Long R. A process for the inclusion of Aboriginal people in health research: Lessons from the determinants of TB transmission project. Soc Sci Med 2011;72:733-8.

9. Clarke M, Riben P, Nowgesi E. The association of housing density, isolation and tuberculosis in Canadian First Nations communities. Int J Epidemiol 2002;31:940-5.

10. Gaudette LA, Ellis E. Tuberculosis in Canada: A focal disease requiring distinct control strategies for different risk groups. Tuberc Lung Dis 1993;74:244-53.

11. Pepperell C, Chang AH, Wobeser W, Parsonnet J, Hoeppner V. Local epidemic history as a predictor of tuberculosis incidence in Saskatchewan Aboriginal communities. Int J Tuberc Lung Dis 2011;15:899-905.

12. Grzybowski S. Epidemiology of TB and the role of BCG. Clin Chest Med 1980;1:175-87.

13. Houston CS. RG Ferguson: Crusader against tuberculosis. Canadian Medical Lives; No 17. Toronto: Dundurn Press Limited, 1991.

14. Ferguson RG. Tuberculosis among the Indians of the great Canadian plains. Trans Nat Assoc Prev Tuberculosis, London, 1928;14:5-56.

15. Graham-Cumming G. The Health of the Original Canadians, 1867-1967. Med Serv J 1967;23:115-66.

16. Young TK. Indian Health Services in Canada: A sociohistorical perspective. Soc Sci Med 1984;18:257-64.

17. Stone EL. Tuberculosis among the Indians of the Norway House Agency. Publ Health J 1925;16:76-81.

18. Young TK. Epidemiology of tuberculosis in remote native communities. Can Fam Physician 1982;28:67-74.
19. Blackwood KS, Al-Azem AL, Elliott LJ, Hershfield ES, Kabani AM. Conventional and molecular epidemiology of tuberculosis in Manitoba. BMC Infect Dis 2003;3:18.

20. Waldram JB. As Long as the Rivers Run. Hydroelectric Development and Native Communities in Western Canada. Winnipeg: University of Manitoba Press, 1988.

21. Lönnroth K, Jaramillo E, Williams BG, Dye C, Raviglione M. Drivers of tuberculosis epidemics: The role of risk factors and social determinants. Soc Sci Med 2009;68:2240-6.

22. Larcombe L, Nickerson P, Singer M, et al. Housing conditions in 2 Canadian First Nations Communities. Int J Circumpolar Health 2011;70:141-53.

23. Chandler MJ, Lalonde C. Cultural continuity as a hedge against suicide in Canada's First Nations. Transcult Psychiatry 1998;35:191-219.

24. Chandler MJ, Lalonde CE. Cultural continuity as a protective factor against suicide in First Nations youth. Horizons 2008;10:68-72.

25. Norris MJ, Clatworthy S. Aboriginal mobility and migration within urban Canada: Outcomes, factors and implications. In: Newhouse D, Peters E, eds. Not Strangers in These Parts: Urban Aboriginal Peoples. Ottawa: Policy Research Initiative, 2003:51-78.

26. Aspler A, Chong H, Kunimoto D, et al. Sustained intra- and interjurisdictional transmission of tuberculosis within a mobile, multiethnic social network: Lessons for tuberculosis elimination. Can J Public Health 2010;101:205-9.

27. Cummings KC, Mohle-Boetani J, Royce SE, Chin DP. Movement of tuberculosis patients and the failure to complete antituberculosis treatment. Am J Respir Crit Care Med 1998;157:1249-52.

28. Long R, Boffa J. High HIV-TB co-infection rates in marginalized populations: Evidence from Alberta in support of screening TB patients for HIV. Can J Public Health 2010;101:202-4.

29. Becker ML, Kasper K, Pindera C, et al. Characterizing the HIV epidemic in the prairie provinces. Can J Infect Dis Med Microbiol 2012;23:19-22.

30. Radley DC, Schoen C. Geographic variation in access to care - the relationship with quality. N Engl J Med 2012;367:3-6.

31. Young TK, Casson RI. The decline and persistence of tuberculosis in a Canadian Indian population: Implications for control. Can J Public Health 1988;79:302-6.

32. Jensen M, Lau A, Langlois-Klassen D, Boffa J, Manfreda J, Long R. A population-based study of tuberculosis epidemiology and innovative service delivery in Canada. Int J Tuberc Lung Dis 2012;16:43-9.

33. Schnarch B. Ownership, control, access, possession (OCAP) or self determination applied to research: A critical appraisal of contemporary First Nations research and some options for First Nations communities. J Aboriginal Health 2004;1:80-94

34. CIHR. Guidelines for health research involving Aboriginal people. Ottawa: CIHR, 2007.<www.cihr-irsc.gc.ca/e/29134.html (Accessed June 18, 2011). 


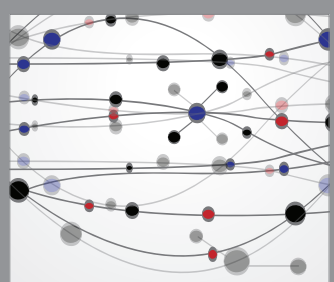

The Scientific World Journal
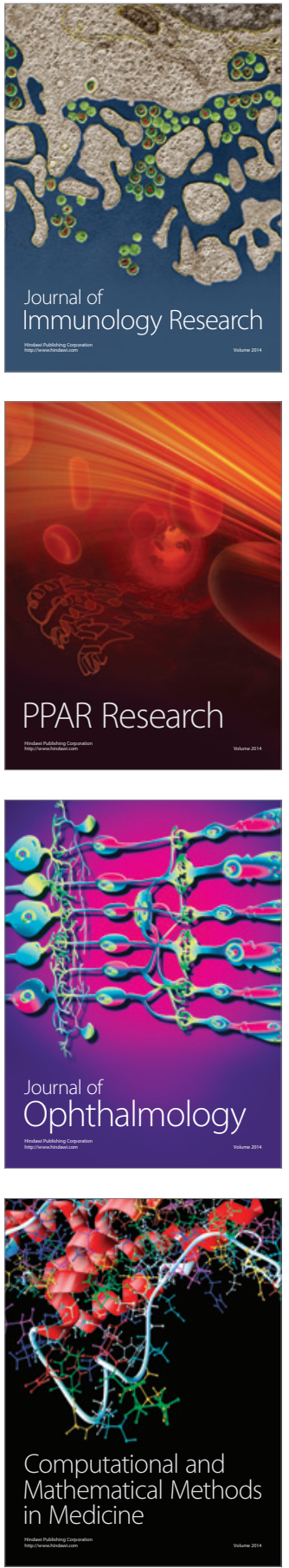

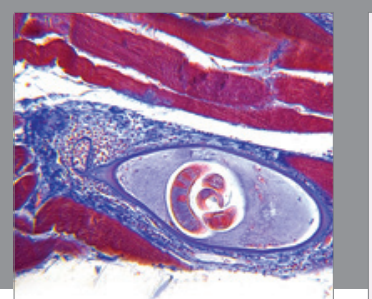

Gastroenterology Research and Practice

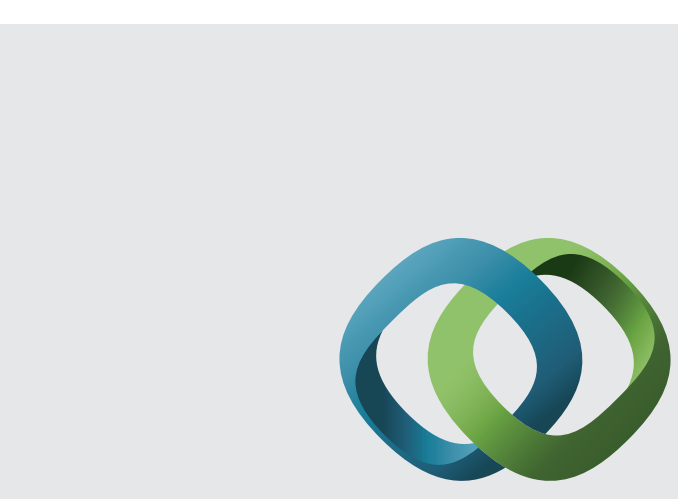

\section{Hindawi}

Submit your manuscripts at

http://www.hindawi.com
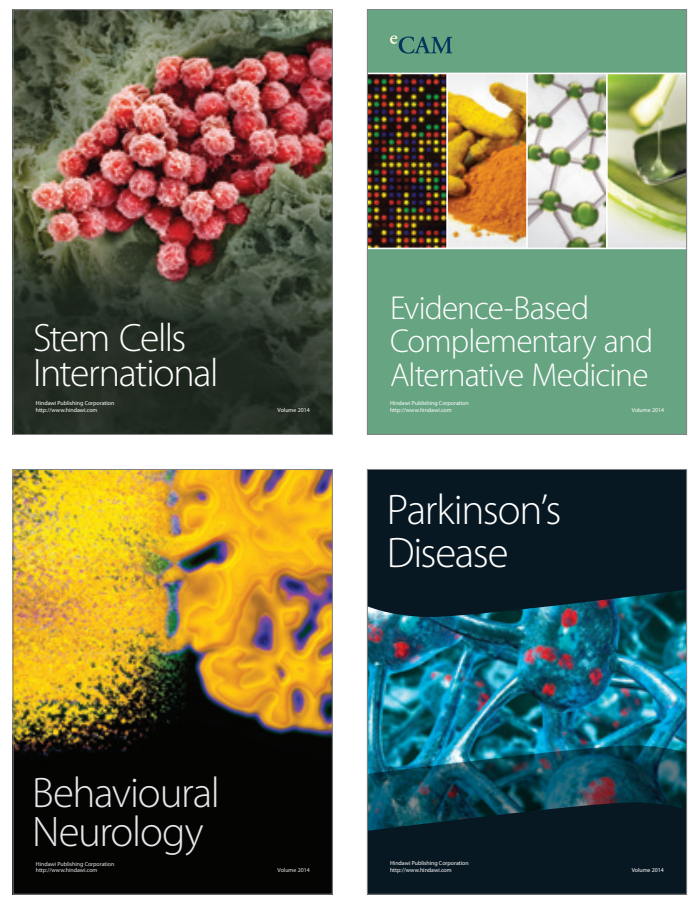
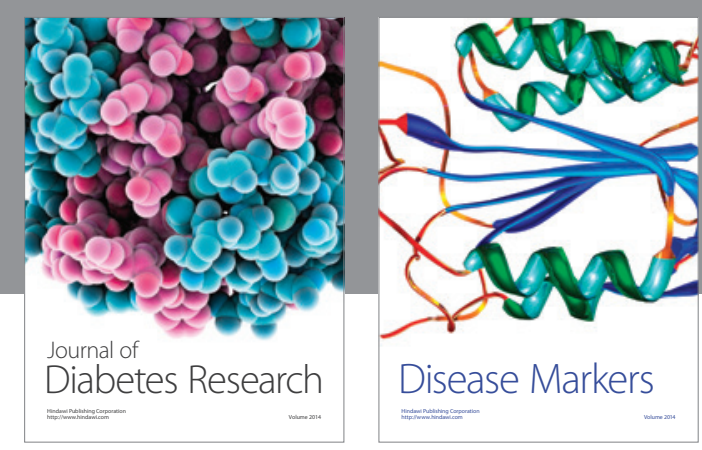

Disease Markers
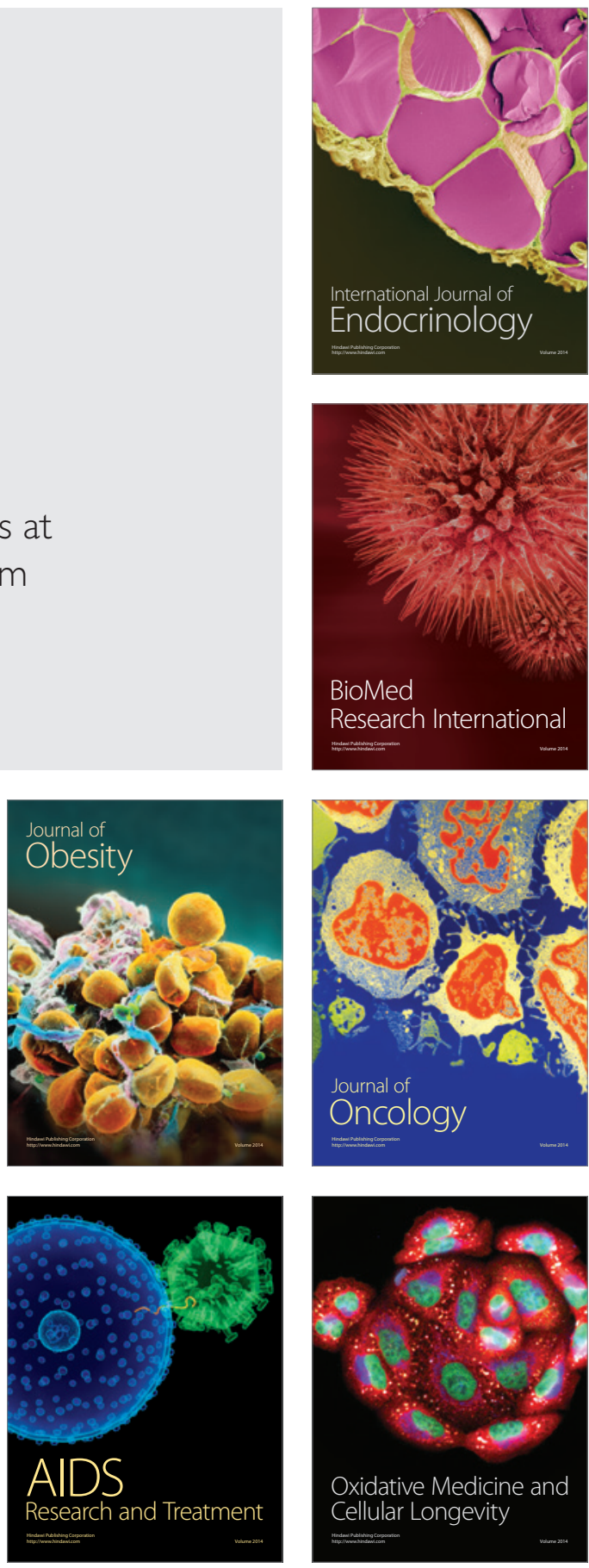